\title{
DIFERENÇA ALTIMÉTRICA DOS RIOS DAS CAVERNAS ANGÉLICA, TERRA RONCA E SÃO BERNARDO DO SISTEMA CÁRTSTICO TERRA RONCA, GOIÁS
}

\author{
Yan de Mello Aleixo ${ }^{(a)}$, Márcio Henrique de Campos Zancopé ${ }^{(b)}$ \\ (a) Instituto de Estudos Socioambientais, Universidade Federal de Goiás, yanma.095@gmail.com \\ (b) Instituto de Estudos Socioambientais, Universidade Federal de Goiás, zancope@ufg.br
}

\section{EIXO: SISTEMAS GEOMORFOLÓGICOS: ESTRUTURA, DINÂMICAS E PROCESSOS}

\begin{abstract}
Resumo
Rios que atravessam sistemas cárticos podem depositar sedimentos dependo da relação entre gradiente fluvial, velocidade da corrente e aporte sedimentar. Este trabalho apresenta a diferença altimétrica de três sistemas de cavernas do Parque Estadual Terra Ronca, nordeste de Goiás, classificando a capacidade de evacuação de sedimentos. Para tanto, foram analisados as formas dos perfis longitudinais, elaborados a partir da rede de drenagem restituída (escala 1:10.000) e MDE (TOPODATA, $30 \mathrm{~m}$ ). O sistema do Rio São Bernardo possui maior diferença altimétrica sumidouroressugência, seguido pelo sistema Terra Ronca (Rio da Lapa) e por último o sistema do Rio Angélica. Enquanto o sistema São Bernardo apresentaria maior capacidade de evacuar sedimentos das cavernas, o sistema Angélica apresentaria maior possibilidade de assoreamento nas cavernas.
\end{abstract}

Palavras chave: fluvicárste. perfil longitudinal. assoreamento.

\section{Introdução}

A variação altimétrica (gradiente) dos rios pode ser descrita pelo perfil longitudinal, seja desde as nascentes até o exutório, ou de trechos fluviais (CHRISTOFOLETTI, 1981). Trechos, cujos perfis longitudinais apresentam gradientes elevados, a velocidade da corrente é acentuada, permitindo maior transporte de sedimentos. Inversamente, em gradientes muito baixos, a velocidade é lenta e o transporte torna-se limitado (CUNHA, 1994), favorecendo a ocorrência de depósitos de sedimentos.

Rios que atravessam sistemas cársticos também dependem dessas relações entre gradiente, velocidade da corrente e aporte sedimentar. Piló (2000) e Laureano, Karmann e Granger (2013) mencionam a ocorrência de depósitos alóctones em cavernas de São Paulo e da Bahia, elucidando a evolução daqueles sistemas cársticos.

O sistema cárstico do Parque Estadual Terra Ronca, no nordeste de Goiás, têm rios atravessando os condutos principais, transportando sedimentos alóctones ao cárste. Este trabalho apresenta as diferenças altimétricas dos rios subterrâneos das cavernas Angélica, Terra Ronca e São Bernardo, classificando os rios que apresentam maior capacidade para evacuação de sedimentos das cavernas e os que apresentam maior possibilidade de assoreamento no interior das cavernas. 


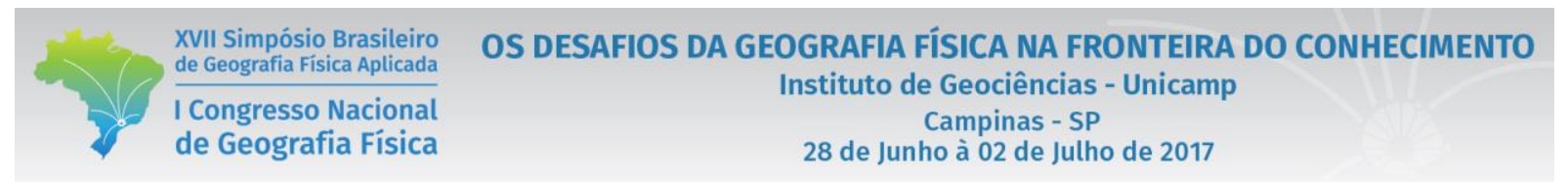

Outro desafio consistiu em conciliar um mapeamento detalhado da drenagem, a ausência dos comprimentos dos trechos fluviais subterrâneos e as limitações dos dados altimétricos para escalas de detalhe. Este trabalho apresenta resultados preliminares, os quais orientarão atividades de campo para correção dos dados altimétricos indiretos, fornecidos pela fontes disponíveis.

\section{Materiais e Método}

A área de estudo localiza-se no nordeste do estado de Goiás, compreendendo os rios admitidos pelos sumidouros das cavernas Angélica, Terra Ronca e São Bernardo, sendo o rio da primeira um contribuinte da sub-bacia do Rio São Vicente e os dois outros contribuintes da sub-bacia do Rio São Mateus (Figura 1), todos integrantes do Sistema Cárstico do Parque Estadual Terra Ronca (PETeR).

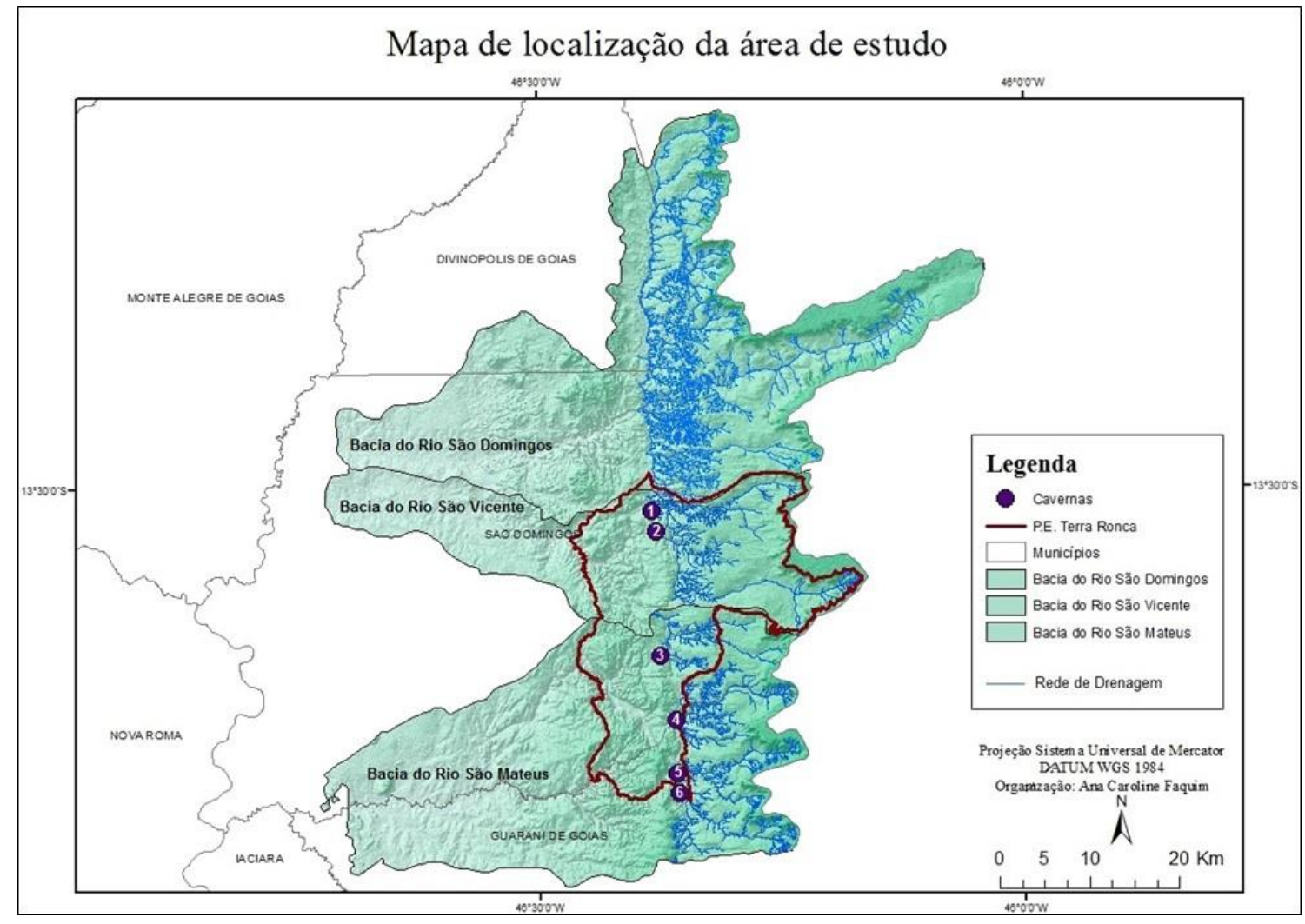

Figura 1 - Área de estudo. Fonte: Faquim (2017).

A área apresenta, a leste, as escarpas da Serra Geral de Goiás (limite Goiás-Bahia) sustentada pelos arenitos do Grupo Urucuia. Os rios, que nascem nesta serra, drenam para oeste sobre restrita superfície aplainada, medianamente dissecada, embutida no sopé da Serra Geral (BRASIL, 1982). Os rios, objeto deste trabalho, formam sumidouros ao alcançar o Grupo Bambuí, e passam a escoar subterraneamente, constituindo o Sistema Cárstico Terra Ronca (LATRUBSSE; CARVALHO, 2006). 


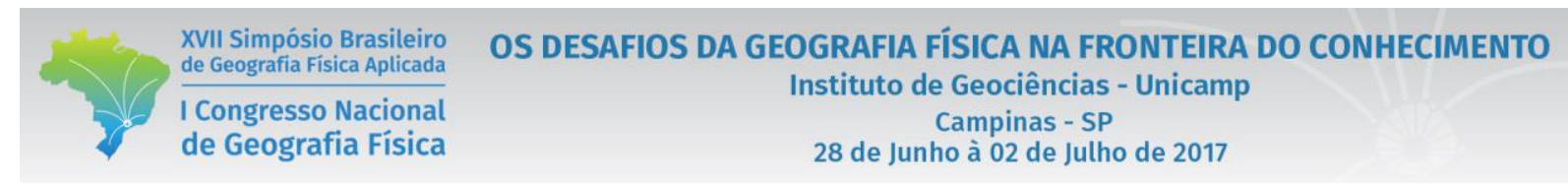

Para a elaboração dos perfis longitudinais, a rede de drenagem foi vetorizada a partir fotos aéreas verticais (escala 1:10.000), da SECIMA e demais imagens de satélite de alta resolução. A altimetria foi obtida a partir dos Modelos Digitais de Elevação (MDE), elaborados com os dados TOPODATA (resolução 30 m), do IBGE.

O modelo topográfico foi confecionado através da ferramenta de Rede Triangular Irregular (TIN), gerada a partir do MDE, processadas no software ERSI ${ }^{2} A r c G i s ~ 10.2$. Uma vez restituída a rede de drenagem, foram isolados os rios que tem como exutório as cavernas selecionadas. Os perfis topográficos desses rios foram elaborados a partir do cruzamento desses dados vetoriais com o TIN (escala 1:10.000).

\section{Resultados e Discussão}

O Rio Angélica pertence à bacia do Rio São Vicente, abastecendo o sistema de cavernas Angélica. Ele percorre 22,3 km até os maciços cársticos do Grupo Bambuí, onde é admitido pelas galerias subterrâneas. O trecho subterrâneo, entre o sumidouro e a ressurgência, possui uma diferença altimétrica de $25 \mathrm{~m}$ (Figura 2). Após atravessar todo o endocarste, ele percorre mais $3 \mathrm{~km}$ e desagua no Rio São Vicente, completando o comprimento total de $29,4 \mathrm{~km}$, estimando o percurso subterrâneo de $4 \mathrm{~km}$, a partir de Rubbioli (1998).

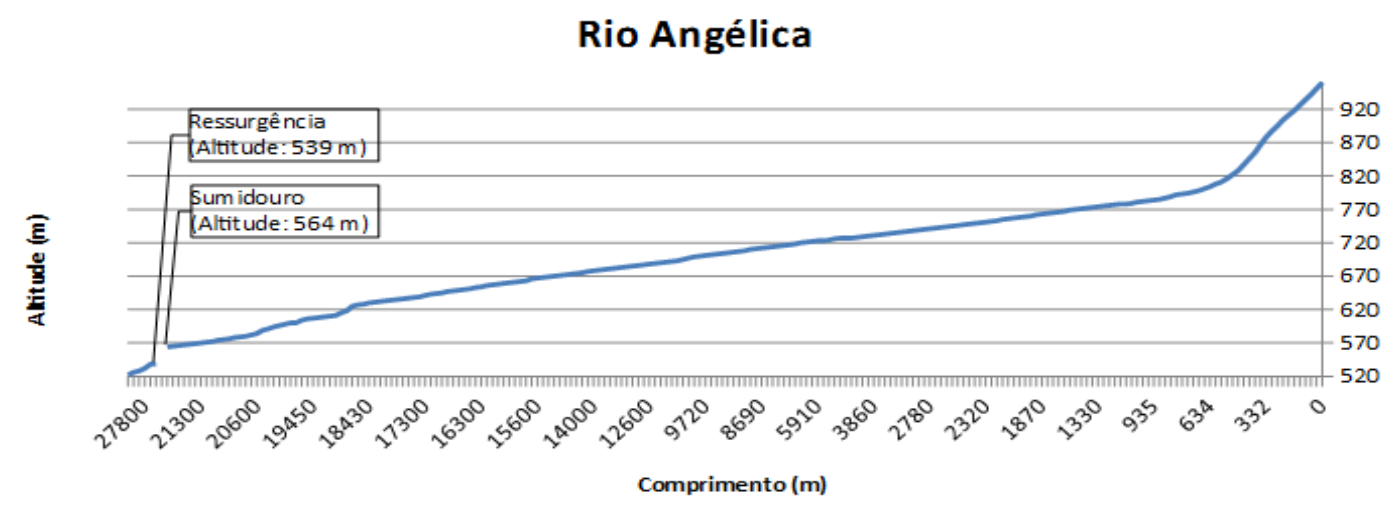

Figura 2 - Perfil longitudinal do Rio Angélica.

O Rio da Lapa pertence a bacia do Rio São Mateus, abastecendo os sistemas de cavernas Terra Ronca I e II. Ele corre no sentido E-W, atravessando 17,6 km até chegar ao sumidouro. Após seu trecho subterrâneo, percorre mais $10 \mathrm{~km}$ a jusante da ressurgência até desaguar no Rio São Mateus, completando um percurso total de $31 \mathrm{~km}$ (Figura 3). Durante o trecho subterrâneo, o rio percorre aproximadamente $2 \mathrm{~km}$ de extensão (estimado a partir de feições exocársticas) com uma diferença altimétrica de $48 \mathrm{~m}$ entre o sumidouro e a ressurgência. 


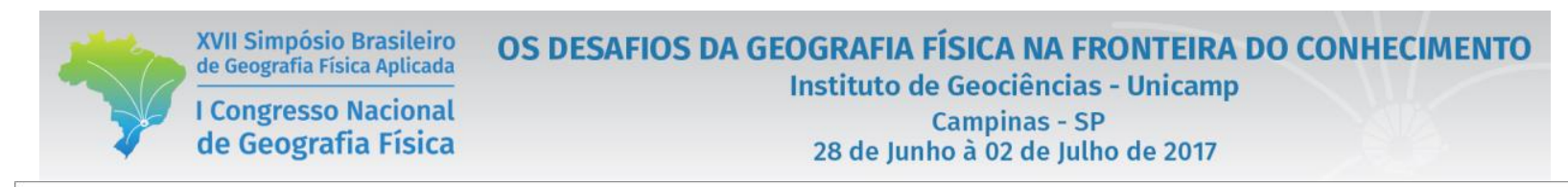

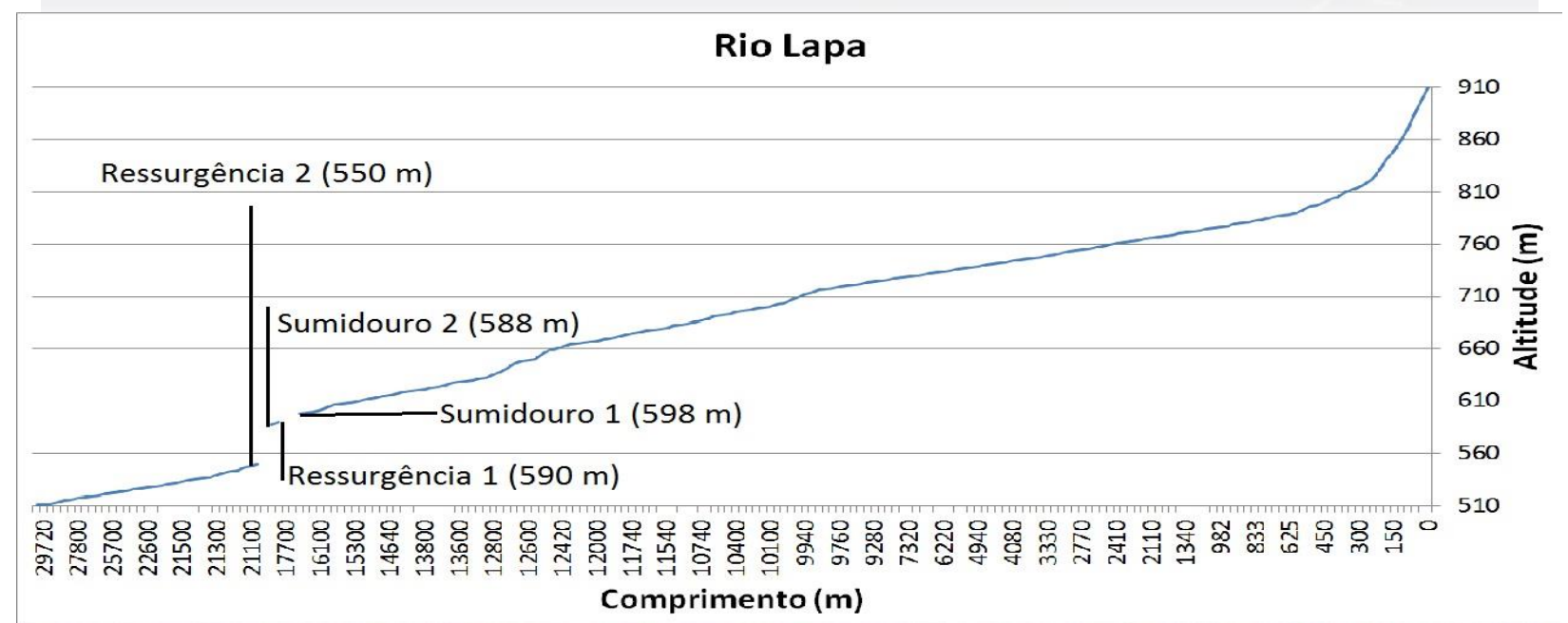

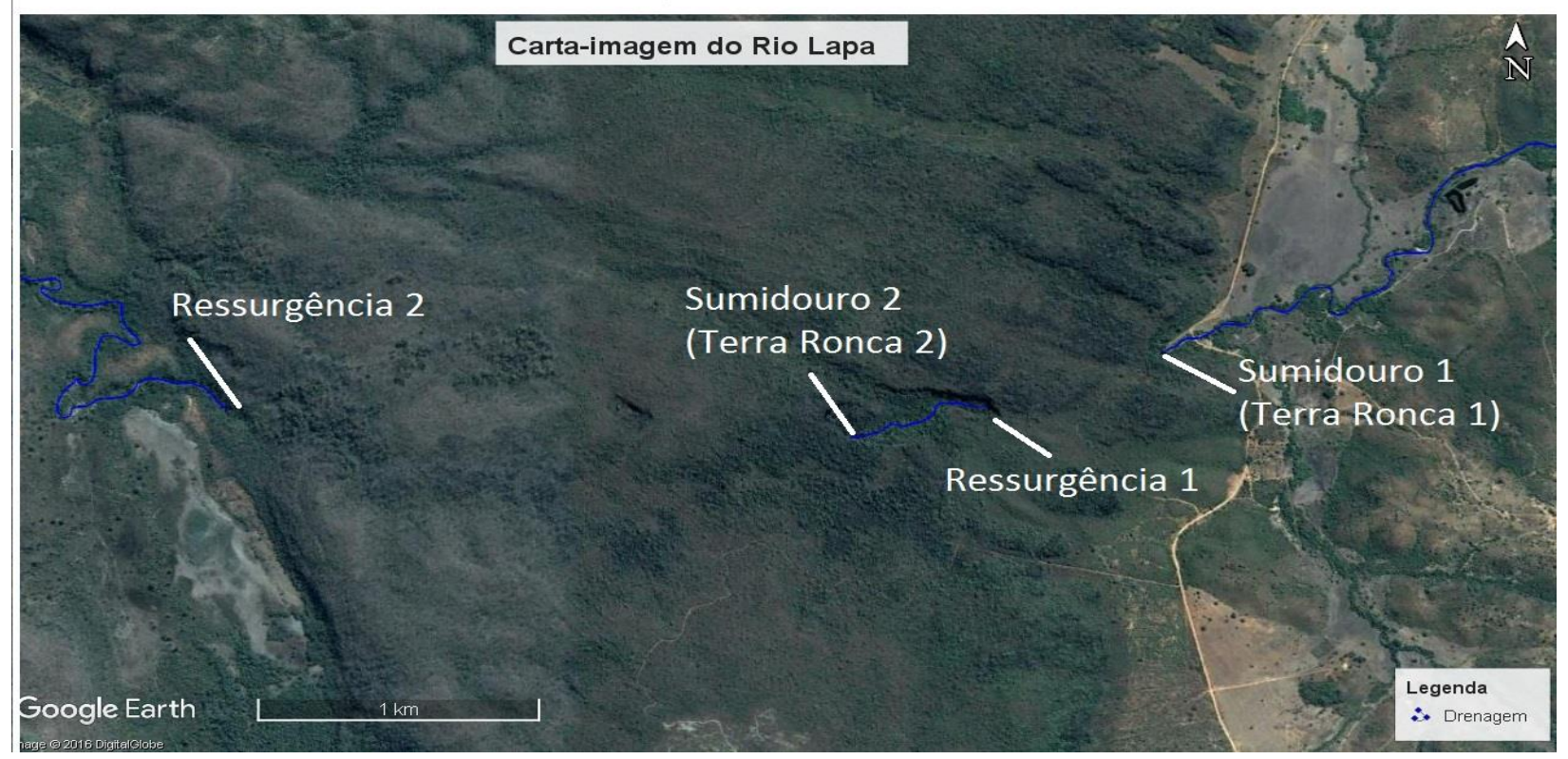

Figura 3 - Perfil longitudinal do Rio Lapa.

Há dois trechos subterrâneos nesse rio separados por um vale cego de $700 \mathrm{~m}$ aproximadamente, resultante do desabamento do conduto principal. A primeira ressurgência delimita a extensão da caverna Terra Ronca I e o sumidouro a jusante o início da Terra Ronca II. Quando termina o sistema de cavernas, o rio ressurge em um cânion a $21 \mathrm{~km}$ da nascente, e percorre mais $10 \mathrm{~km}$ até chegar a foz.

O Rio São Bernardo é outro afluente da bacia do Rio São Mateus, contribuindo com os sistemas de cavernas São Bernardo I, II e III. Percorre 18,4 km no sentido E-W até atingir o complexo de cavernas. O trecho subterrâneo (sumidouro-ressurgência), possui uma diferença altimétrica de $88 \mathrm{~m}$. O sistema do Rio São Bernardo desenvolve três complexos de cavernas em 10,6 km, estimado a partir das feições 
exocársticas e de Perret (1998). O rio ressurge num cânion até desaguar no Rio São Mateus, completando um percurso total de $58,6 \mathrm{~km}$.

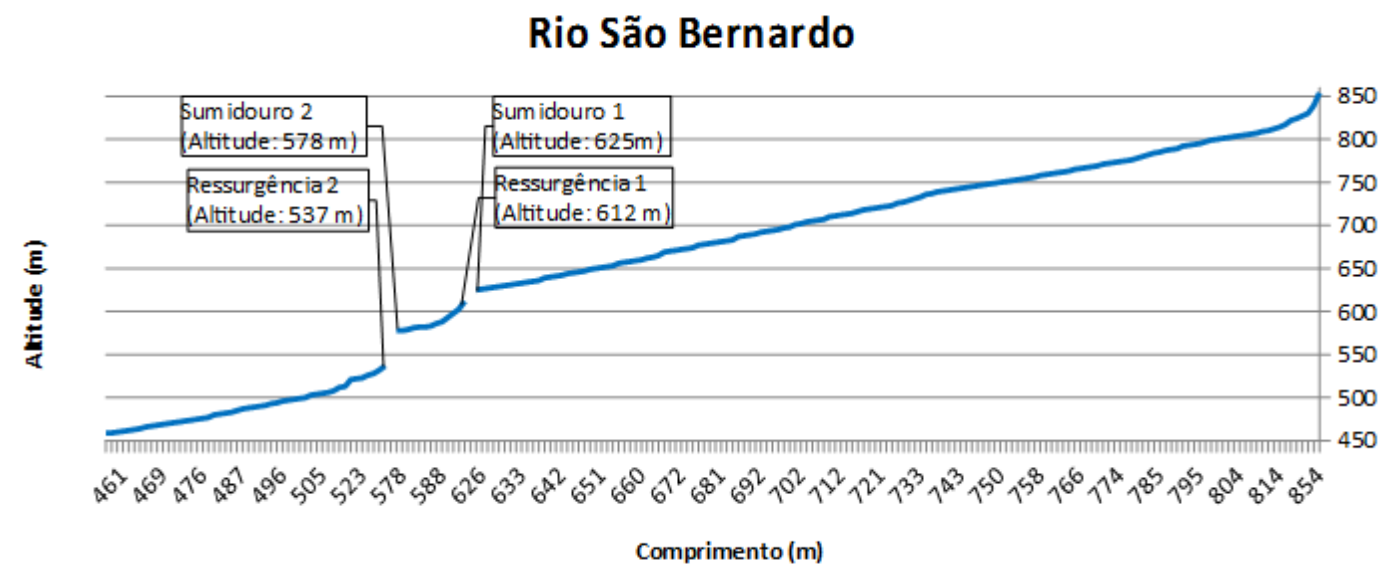

Figura 4 - Perfil longitudinal do Rio São Bernardo.

\section{Conclusão}

Os rios Angélica, Lapa e São Bernardo se assemelham em relação as nascentes localizadas na Serra Geral, e atravessam o PETeR. Entretanto, as bacias que estes contribuem são distintas: o Rio Angélica pertence a bacia do Rio São Vicente, enquanto os demais rios são da bacia do Rio São Mateus. Esses sistemas fluviais constituem uma grande importância espeleológica, por formarem amplos sistemas endocarsticos. Os perfis longitudinais dos rios sugerem os trechos que ocorrem erosão, transporte e deposição. Entretanto, a deficiência de mapeamentos para os trechos subterrâneos dificulta a análise dos perfis. A diferença altimétrica entre os sumidouros e ressurgências sugere que o sistema do S. Bernardo possui maior capacidade de evacuação de sedimentos, seguido pelo sistema Terra Ronca (Rio da Lapa) e por último o sistema do Rio Angélica. Enquanto o sistema de São Bernardo apresentaria maior capacidade de evacuar sedimentos das cavernas, o sistema do Angélica apresentaria maior probabilidade de assorear sedimentos do interior das cavernas.

\section{Agradecimentos}

Agradecemos ao CNPq e a Universidade Federal de Goiás (UFG) pelo apoio financeiro ao projeto de pesquisa pela Chamada Universal MCTI-CNPq (processo n. 461869/2014-4) e pela concessão de bolsa de Iniciação Científica (PIBIC-UFG), que permitiram o desenvolvimento deste trabalho. 


\section{Referências}

BRASIL. Ministério das Minas e Energia. Projeto radambrasil: levantamento de recursos naturais, Folha SD.23 Brasília. Rio de Janeiro, 1982. Vol. 29.

CHRISTOFOLETTI, A. Geomorfologia fluvial: o canal fluvial. São Paulo: Edgard Blücher, 1981.

CUNHA, S.B. Geomorfologia fluvial. In: GUERRA, A.J.T.; CUNHA, S.B. (Org.). Geomorfologia: uma atualização de bases e conceitos. Rio de Janeiro: Bertrand Brasil, 1994. cap. 5. p. 211-252.

FAQUIM. A.C.S. Potencial de transferência de sedimentos das bacias contribuintes do sistema cárstico Terra Ronca. 2017. 29f. Trabalho de conclusão de curso (Bacharelado em Ciências Ambientais) - Instituto de Estudos Socioambientais, Universidade Federal de Goiás, Goiânia, 2017.

LATRUBESSE, E.M.; CARVALHO, T.M. Geomorfologia do Estado de Goiás e Distrito Federal. Goiânia: Superintendência de Geologia e Mineração do Est. de Goiás, (2006). (Série Geologia e Mineração, n. 2).

LAUREANO, F.V.; KARMANN, I.; GRANGER, D. Datações preliminares do soterramento de grãos de quartzo por isótopos cosmogênicos em cavernas da Chapada Diamantina indicam agradação nos condutos desde o Pleistoceno Superior. In: CONGRESSO DA ASSOCIAÇÃO BRASILEIRA DE ESTUDOS DO QUATERNÁRIO, 14. Natal (RN), 2013. Anais... Natal: ABEQUA/UFRN, 2013. Disponível em: <http://www.abequa.org.br/trabalhos/geomorfo_2014_17.pdf>. Acessado em: 13/12/2016.

PERRET, J.F. A força do Rio São Bernardo. O Carte, v. 10, n. 4, p. 118-127, 1998.

PILÓ, L.B. Geomorfologia cárstica. Revista Brasileira de Geomorfologia, v. 1, n. 1, p. 88-102, 2000.

RUBIOLLI, E.L. Descobertas e desafios no Sistema Angélica-Bezerra. O Carte, v. 10, n. 4, p. 150-155, 1998. 